\title{
Process Control and Yield Enhancement of the Galacto-Oligosaccharide Formation
}

\author{
Ines Mueller ${ }^{1 \star}$, Gregor Kiedorf ${ }^{2}$, Eike Runne ${ }^{1}$, Ines Pottratz ${ }^{1}$, Andreas Seidel-Morgenstern ${ }^{2,3}$, \\ Christof Hamel ${ }^{1,3}$ \\ ${ }^{1}$ Ines Mueller, Eike Runne, Ines Pottratz, Prof. Dr.-Ing. habil. Christof Hamel, Anhalt University of Applied Sciences, Applied Biosciences and \\ Process Engineering, Bernburger Str. 55, 06366 Koethen, Germany \\ ${ }^{2}$ Dr.-Ing. Gregor Kiedorf, Max Planck Institute for Dynamics of Complex Technical Systems, Sandtorstr. 1, 39106 Magdeburg, Germany \\ ${ }^{3}$ Prof. Dr.-Ing. habil. Andreas Seidel-Morgenstern, Otto von Guericke University, Institute of Process Engineering, Universitaetspl. 2, 39109 \\ Magdeburg, Germany \\ *ines.mueller@hs-anhalt.de
}

Keywords: galacto-oligosaccharides, glucose oxidase, prebiotics, process intensification, sweet whey, $\beta$ galactosidase,

\begin{abstract}
As lactose is an increasing byproduct of dairy industry, the selective conversion to prebiotics galacto-oligosaccharides (GOS) by the enzyme $\beta$-galactosidase represents a highly attractive value creation. The synthesis of GOS is characterized by an equilibrium-limited reaction, which can be overcome by a coupling with an enzymatic reduction of the side product glucose to achieve an increase in product yield. Furthermore, the effect of substrate substitution based on sweet whey and the impact of whey dominating salt ions was examined - leading to a further process intensification of GOS synthesis.
\end{abstract}

\section{Introduction}

The growing health awareness of consumers generates a continuously increasing demand with respect to functional foods and food additives like prebiotics. In particular, a great interest exists in the utilization of galacto-oligosaccharides (GOS) as health-promoting food supplement for infant as well as for elderly people's nutrition. GOS provides due to its prebiotic effect positive physiological and nutritional properties by stimulating the growth of beneficial intestinal bacteria [1].

GOS is a natural part of the human breast milk. In contrast, bovine milk contains GOS as a minor component only. Thus, a promising approach for GOS formation is provided by the enzymatic catalysis of the GOS synthesis from bovine lactose using $\beta$-galactosidase ( $\beta$-gal). As lactose is a steadily increasing side and waste product of the dairy industry [2], respectively, the enzymatic conversion to prebiotic galacto-oligosaccharides offers a value-adding process. Since the enzyme performs in two main reaction steps - hydrolysis and transgalactosylation (fig. 1) - the resulting product mixture contains GOS of different chain lengths, unconverted lactose and the side products galactose and glucose. 
Fig.1

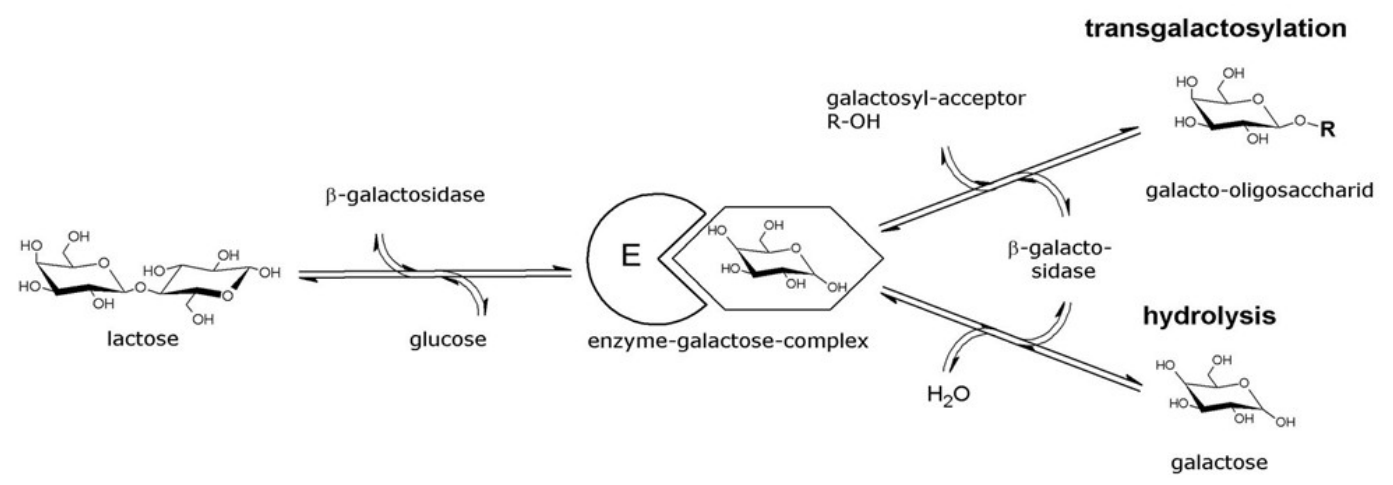

The incomplete conversion of lactose to GOS induces an equilibrium-limited reaction with a restricted product yield. Two approaches for yield enhancement and process optimization will be aim of this contribution. The first aspect deals with the shift of the reaction equilibrium by selective reduction of the side-product glucose by glucose oxidase and the second one for simplification of the process flow by the substitution of the expensive substrate lactose by sweet whey and sweet whey permeate in industry.

\section{Approach I: Shift of the reaction equilibrium by a coupled reaction}

For further increase of the conversion and especially the yield, the reaction equilibrium can be specifically shifted by reduction of the side products due to coupling a selective series reaction. By dynamic dosing of glucose oxidase (GOx, see fig. 2), the side product glucose will be converted by feeding atmospheric oxygen as electron acceptor. In the first reaction step gluconodelta-lacton will be formed which can be spontaneously transformed to gluconic acid under detachment of hydrogen peroxide. For suppression of intoxication / inhibition of $\beta$-galactosidase a neutralization agent (catalase) needs to be added to degrade hydrogen peroxide to water and oxygen. Additionally, the acid-base balance of the solution needs to be maintained at $\mathrm{pH}$ optimum of $\beta$-galactosidase by the neutralization the gluconic acid by dosing calcium carbonate or sodium hydroxide forming either calcium gluconate or sodium gluconate.

Fig. 2

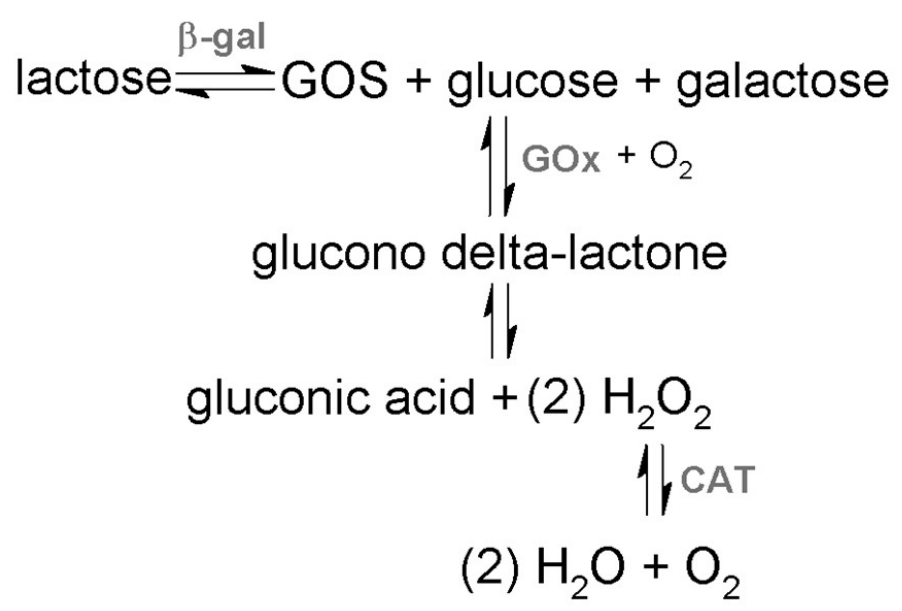




\section{Approach II: Process Intensification by substrate substitution}

The second example for process intensification is the substitution of the substrate lactose by sweet whey or sweet whey permeate. The most promising advantage is an improvement in terms of process simplification and optimization. When reflecting upon the production process of lactose powder the liquid sweet whey with $6 \%$ dry matter needs to be heated, purified, vacuum evaporated, crystallized (up to $24 \mathrm{~h}$ ), decanted and run through a final drying to achieve a dry product less than $1 \%$ water [3]. The overall process flow of lactose is a thermal energy and timeconsuming procedure, which can be strongly reduced by the substitution of the purified substrate lactose with conventional sweet whey or sweet whey permeate available in the conventional dairy processes. Whey powder in contrast includes overall three process stages from the liquid to powder: separation, evaporation, and spray drying [3]. As sweet whey/permeate powder contains further ingredients besides lactose such as proteins, fat, lactic acid, minerals and others, they may affect the GOS reaction mechanism. Due to the fact that specific minerals are commonly known for their coenzyme/activator properties, they have a crucial role in the support or suppression of the enzymatic activity. Sweet whey dominating salt ions per $100 \mathrm{~g}$ whey powder are potassium with $1855 \mathrm{mg}$, sodium $1287 \mathrm{mg}$, phosphorous $1096 \mathrm{mg}$, calcium $878 \mathrm{mg}$, magnesium $178 \mathrm{mg}$ (approx.) and other minor minerals lower than $10 \mathrm{mg}$ [4]. The influence of these selected whey dominating salt ions will be investigated in this contribution to evaluate the feasibility and potential for the substitution of lactose by sweet whey and sweet whey permeate powder.

\section{Materials and Methods}

\section{Chemicals}

For synthesis and analytical calibration carbohydrates from Carl Roth $\mathrm{GmbH}+\mathrm{Co}$. KG (Karlsruhe, Germany) were utilized: $\mathrm{D}(+)$-galactose (purity $\geq 98 \%$ ), lactose monohydrate (purity $\geq 99.5 \%$ ), $\mathrm{D}(+)$-glucose monohydrate (purity $\geq 99.5 \%$ ), di-sodium hydrogen phosphate dihydrate $\left(\mathrm{Na}_{2} \mathrm{HPO}_{4} \cdot 2 \mathrm{H}_{2} \mathrm{O}\right.$; purity $\left.\geq 99.5 \%\right)$, di-potassium hydrogen phosphate $\left(\mathrm{KH}_{2} \mathrm{PO}_{4}\right.$; purity $\left.\geq 99.5 \%\right)$, magnesium chloride $\left(\mathrm{MgCl}_{2}\right.$, purity $\left.\geq 98.5 \%\right)$, TRIS (purity $\geq 99.9 \%$ ), o-nitrophenyl- $\beta-\mathrm{D}$ galactopyranoside (o-NPG, purity $>99 \%$ ).

Further chemicals were purchased from Applichem $\mathrm{GmbH}$ (Darmstadt, Germany): potassium chloride (purity $\geq 99.5 \%$ ), sodium chloride (purity $\geq 98.5 \%$ ) and calcium chloride (purity $\geq 99.0 \%)$.

GOS a certified DOMO $^{\circledR}$ Vivinal $^{\circledR}$ GOS syrup (article 596667) with $44.25 \%$ galactooligosaccharides was kindly provided by Friesland Campina (Amersfoort, The Netherlands).

Sweet whey powder from Lactoland (Duelmen, Germany) consists of $72.8 \%$ lactose, $10.9 \%$ protein, $8.2 \%$ minerals, $1.5 \%$ organic acids, $1.1 \%$ fat and $4.4 \%$ water. Sweet whey permeate 
powder from Lactoland (Duelmen, Germany) comprises $85.0 \%$ lactose, $8 \%$ minerals, $3 \%$ proteins, $\leq 1.5 \%$ fat and $\leq 4 \%$ water.

\section{Analysis of Carbohydrates}

The carbohydrate analysis was performed by HPLC with a Hi-Plex Na column $(300 \times 7.7 \mathrm{~mm}$ with a guard cartridge $5 \times 3 \mathrm{~mm}$ ) from Agilent Technologies (Frankfurt/Main, Germany). Ultrapure water as mobile phase with a flow rate of $0.3 \mathrm{~mL} \mathrm{~min}^{-1}$ at $85^{\circ} \mathrm{C}$ and an injection volume of $10 \mu \mathrm{L}$ was used. GOS was calibrated with the $\mathrm{DOMO}^{\circledR}$ Vivinal ${ }^{\circledR}$ GOS syrup. Glucose, galactose and lactose were each calibrated separately. The signal was detected by a refractive index detector 'Chromaster 5450' from VWR Hitachi and analysed by Agilent OpenLAB CDS EZChrom software (Agilent Technologies, Inc.).

\section{Enzymes and experimental setup}

For experiments with glucose oxidase $4.5 \mathrm{U} \mathrm{mL}^{-1} \beta$-galactosidase from Kluyveromyces lactis/K. lactis 'Maxilact ${ }^{\circledR}$ LX5000' from DSM (Heerlen, The Netherlands), $4.5 \mathrm{U} \mathrm{mL}^{-1} \mathrm{GOx}$ from Penicillium chrysogenum 'Sumizyme PGO' from Shin Nihon Chemical (Anjo, Japan) and $4.5 \mathrm{U} \mathrm{mL}^{-1} \mathrm{CAT}$ from Micrococcus lysodeiktikus from Sigma-Aldrich (Steinheim, Germany) were used. The initial lactose concentration was $90 \mathrm{~g} \mathrm{~L}^{-1}$ in a $0.1 \mathrm{~mol} \mathrm{~L}^{-1}$ phosphate buffer solution $\left(\mathrm{Na}_{2} \mathrm{HPO}_{4}+\mathrm{KH}_{2} \mathrm{PO}_{4}\right)$ with a $\mathrm{MgCl}_{2}$ concentration of $1 \mathrm{mM} \mathrm{L}^{-1}$ at $\mathrm{pH}$ 6.5. The batch size of $500 \mathrm{~mL}$ got tempered at $40{ }^{\circ} \mathrm{C}$ in a BIOSTAT ${ }^{\circledR}$ B from Sartorius Stedim Biotech $\mathrm{GmbH}$ (Goettingen, Germany) containing a paddle agitator applied at $300 \mathrm{rpm}$ stirring frequency and an aeration with atmospheric oxygen at a rate of $1 \mathrm{Lpm}$. The oxygen saturation of the reaction mixture was recorded with a $\mathrm{pO}_{2^{-}}$ electrode, setting the maximum oxygen saturation of the initial substrate without enzymes at $40^{\circ} \mathrm{C}$ to $100 \%$. The enzyme species were dosed at once and present the initial starting point of the reaction. The $\mathrm{pH}$ was adjusted during synthesis fully automated with a $1 \mathrm{~mol} \mathrm{~L}^{-1} \mathrm{NaOH}$ solution by the bioreactor system and the caused concentration change counted back within the HPLC analysation. Samples were taken once every 10 minutes until 60 minutes and subsequently each hour. Enzyme activity of the samples were immediately stopped within three minutes in a $90{ }^{\circ} \mathrm{C}$ hot water bath. For evaluation of the measured data the parameters GOS yield, glucose formation and lactose conversion were used. The yield of GOS as well as the glucose formation is defined by the product mass concentration divided by the initial substrate mass concentration in percent. The lactose conversion is calculated by the ratio of the residual lactose to the initial lactose concentration in percent.

The catalyst as well as the substrate gets completely dissolved in the reaction media. In assumption of the enzyme-substrate-ratio remains constant, the change in volume caused by the sampling process was neglected for further calculations. 
The impact of whey and salt ions was performed with $4.5 \mathrm{U} \mathrm{mL}^{-1} \beta$-galactosidase from Escherichia coli/E. coli from Sigma-Aldrich (article 48275, Taufkirchen, Germany) at $40{ }^{\circ} \mathrm{C}$ with an ILC of $100 \mathrm{~g} \mathrm{~L}^{-1}$ dissolved in a $50 \mathrm{mmol} \mathrm{L}{ }^{-1}$ TRIS buffer at $\mathrm{pH}$ 7.0. For the screening of the salt types a concentration of $1 \mathrm{mmol} \mathrm{L}^{-1}$ each solution was applied. For determination of the concentration effect a $1|50| 75 \mid 100 \mathrm{mmol} \mathrm{L}^{-1} \mathrm{KCl}$ solution was tested. Experiments with sweet whey and sweet whey permeate as well as the reference substrate lactose were conducted with a $90 \mathrm{~g} \mathrm{~L}^{-1}$ initial lactose concentration dissolving the powder in a $50 \mathrm{mmol} \mathrm{L}^{-1}$ TRIS buffer. One batch size comprises $40 \mathrm{~mL}$ in a $100 \mathrm{~mL}$ flask stirred at $300 \mathrm{rpm}$ on a "Incubating Minishaker" from VWR (Darmstadt, Germany) at $40{ }^{\circ} \mathrm{C}$. Samples were taken after $0|0.25| 0.5|1| 2|4| 6$ hours. Enzyme activities of the samples were stopped as described before.

The initial enzyme activity of $\beta$-galactosidase was assayed with the same buffer solution as described above for $\beta$-gal from $K$. lactis $(\mathrm{pH} \mathrm{6.5)}$ and $\beta$-gal from E. coli $(\mathrm{pH}$ 7.0). The mixture was tempered at $40{ }^{\circ} \mathrm{C}$ and the change in extinction at $410 \mathrm{~nm}$ recorded for 5 minutes in a spectrophotometer Nanocolor ${ }^{\circledR}$ VIS II from MN (Dueren, Germany) after addition of a $34 \mathrm{mmol} \mathrm{L}^{-1}$ o-NPG substrate. Whereas one unit of active $\beta$-gal is defined by $1.0 \mu$ mol hydrolyzed o-NPG per minute.

\section{Results and discussion}

\section{Approach I: Production of GOS with and without GOx/CAT}

As shown in figure $3 \mathrm{a}$ ), the GOS synthesis obtains a significant change in reaction mechanism under application of GOx/CAT. The conversion of lactose with GOx/CAT is slightly lower than in its reference reaction without GOx/CAT. Furthermore, the curve oft the glucose with the reducing enzymes shows a slightly decrease after 60 minutes, whereas without the additional enzymes much higher formation rates can be observed. The most significant change can be identified in the GOS yield development. The maximum yield of GOS is reached after 20 minutes reaction time for both batches with a neglectable difference: the reference reaction with $31.5 \%$ and $31.3 \%$ for the reaction with GOx/CAT. A similar effect on the GOS yield with glucose oxidase has been determined by Cheng, et al. [5]. But in the continued progression in the batch reaction without GOx/CAT a strong degradation of GOS towards a total loss was shown. As it has been reported by several authors before [6-8] the GOS formation process gets dominated by the GOS degradation after reaching a 60-80 \% lactose conversion. However, this is contradicted to the reaction with GOx/CAT, wherein the GOS yield turns into a stable equilibrium at $\sim 21 \%$ after 120 minutes. But as the reaction rate of $\beta$-gal appears to be much higher than the reaction of GOX/CAT, it can be assumed that a possible benefit of the glucose reduction on the GOS yield will not come into effect. The low reactivity of the GOx/CAT reaction is evident according to the 
limitation of oxygen, as it can be gathered from fig. 3 b). Avoiding the mass transfer limitation by increasing stirrer speed and oxygen flux was not successful. The solubility of oxygen is low in the temperature range covered. As the zero sample is measured before the enzyme dosage, the saturation immediately drops down to zero and recovers slowly after 120 minutes, when the main GOS forming reaction is already concluded. Furthermore, it can be recognized that the addition of GOX/CAT seems to induce a suppression of the $\beta$-gal activity shown in a lower lactose conversion rate and prevention from total GOS degradation. In conclusion, the compatibility of the reaction kinetics of both enzymes has to be adjusted and harmonized as well as a suitable dosing time might be crucial criterions for a working glucose oxidase. Main problem is the mass transfer limitation of oxygen.

Fig. 3
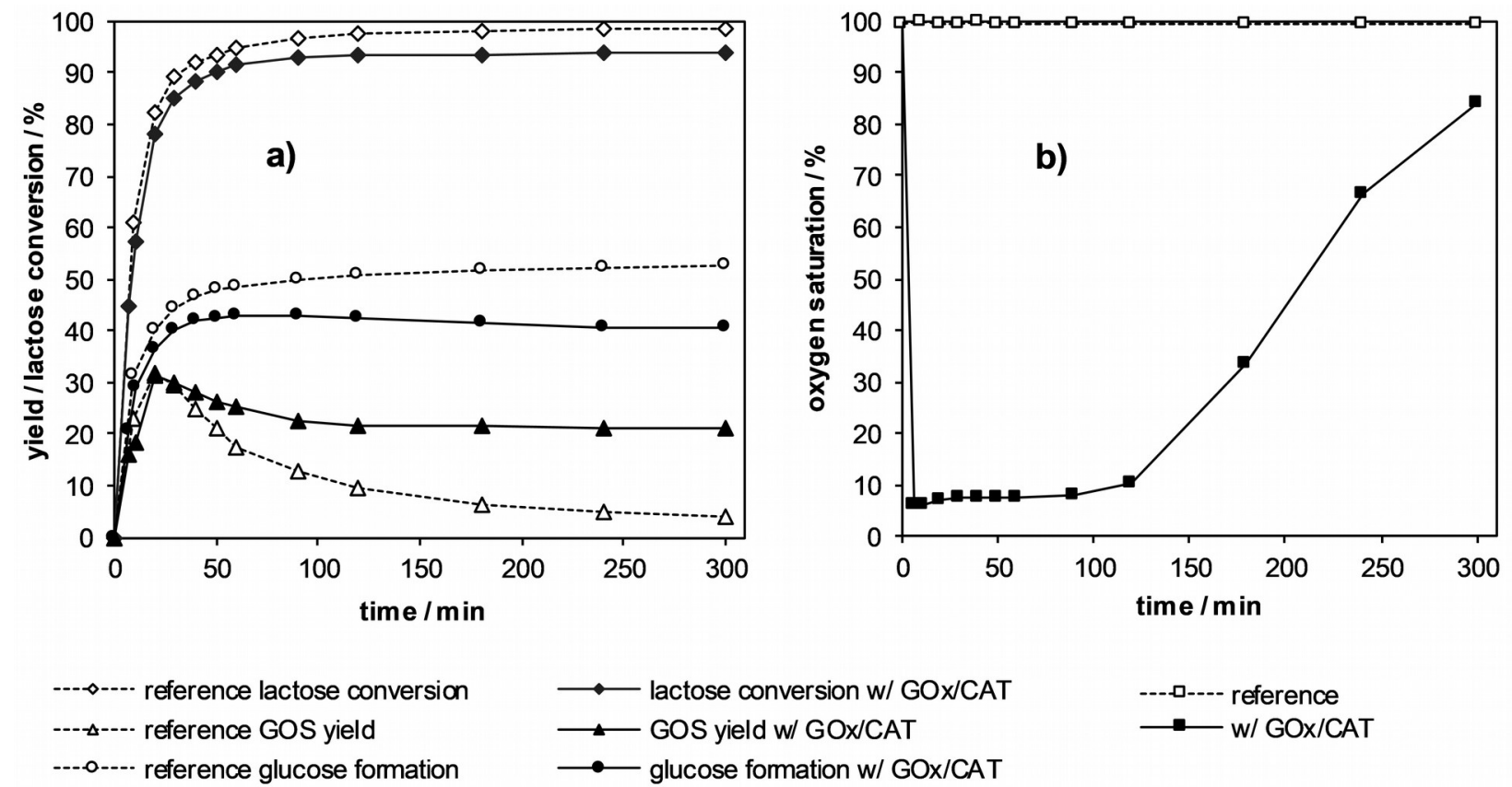

Approach II: Impact of minerals and substrate substitution with sweet whey

The data provided by fig. 4 b) show the results from screening several whey dominating minerals in relation to a salt free batch reaction (TRIS) for the enzyme $\beta$-gal from $E$. coli after six hours. It emerges that potassium chloride, magnesium chloride, and sodium chloride enhance the GOS yield by $4.3 \%$ up to $10.0 \%$. Similar results for $K$. lactis but with o-NPG as substrate have been reported by Fischer et al. [9]. Calcium chloride in contrast obtains an inhibiting effect on the GOS synthesis with an $8.9 \%$ lower yield, while in contrast Huber et al. [10] described for $\mathrm{Ca}^{2+}$ no significant activation or deactivation of $\beta$-gal from $E$. coli. 
Fig. 4
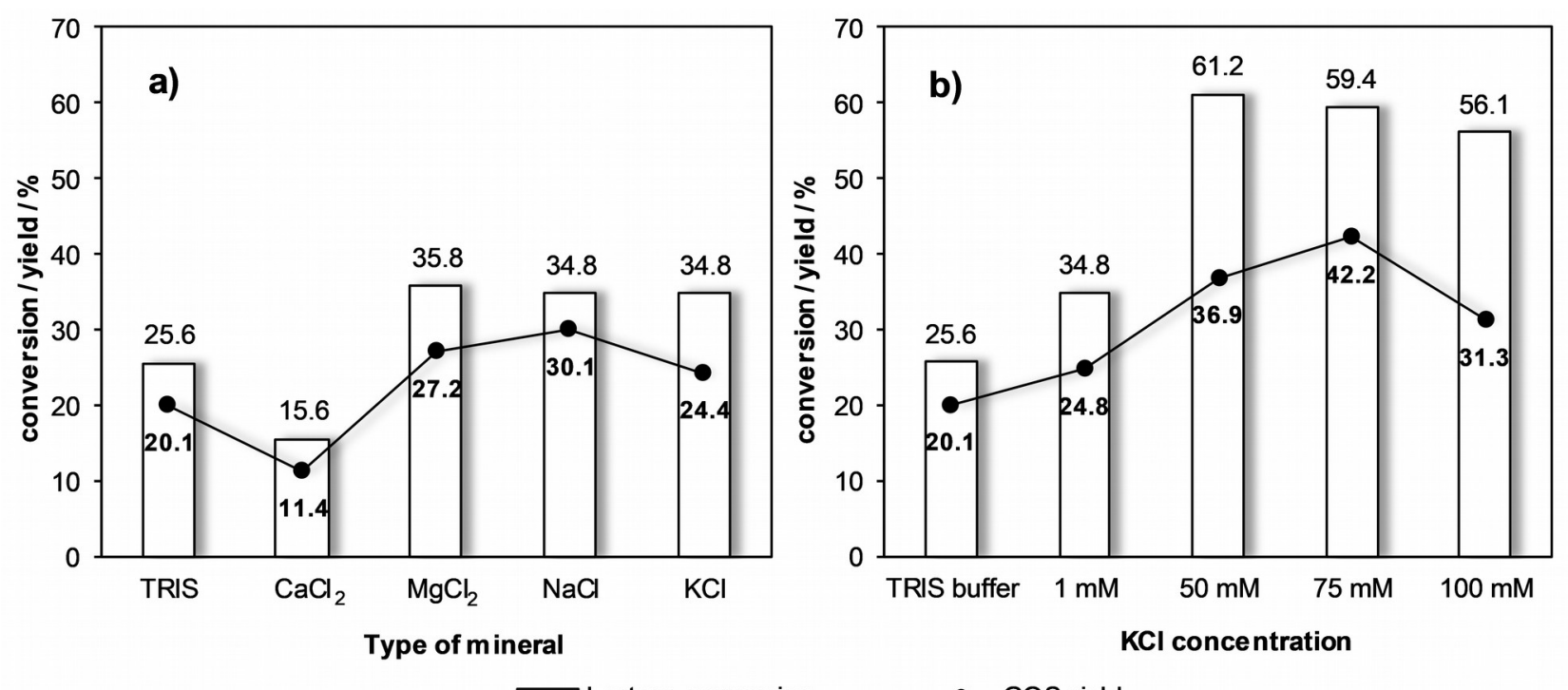

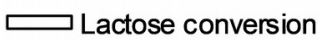

$\longrightarrow$ GOS yield

Figure $4 \mathrm{~b}$ ) illustrates the screening on the impact of the salt concentration between $0 \mathrm{mmol} \mathrm{L}^{-1}$ and $100 \mathrm{mmol} \mathrm{L}^{-1}$ with potassium chloride as one selected example. It is obvious, that a $\mathrm{KCl}$ concentration of $75 \mathrm{mmol} \mathrm{L}^{-1}$ reveals with $22.1 \%$ the highest GOS yield compared to the salt-free reaction after six hours using pure lactose.

As it can be seen in fig. 5, the substitution of lactose by industrial sweet whey or sweet whey permeate obtains a significant positive effect on GOS yield. After six hours $\beta$-gal with lactose substrate produced $15.2 \%$ GOS, whereas sweet whey as substrate reached $19.3 \%$ and sweet whey permeate achieved the highest GOS yield with $21.6 \%$ for the studied conditions.

Fig.5

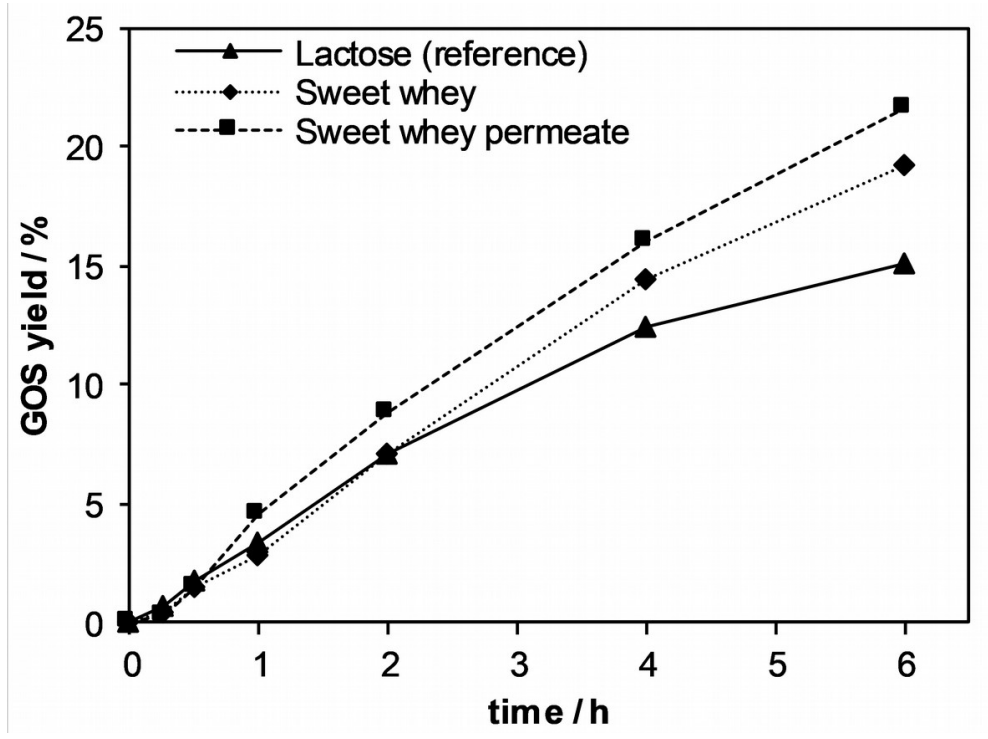


While lactose and fat concentration of both whey substrates are similar, the difference in composition can be found within the mineral and protein concentration. Sweet whey permeate comprises $1.7 \%$ more minerals and $10.3 \%$ more proteins than sweet whey, referring to a $90 \mathrm{~g}$ initial lactose concentration. As dry whey composition is influenced by the produced cheese type and the entire manufacturing process, the product can be described with a highly variable relation between the ingredients. Thus, whey powder can comprise between 65-88 \% lactose, 1-17\% protein, 2-15\% water, 0.5-2 \% fat, 0.1-12 \% lactic acid, 0.7-10\% minerals [11], which justifies its intensive influence in the presented data, but makes a prediction for maximum yield rates by changing raw material properties challenging.

\section{Conclusions}

Multiple number of publications follow up with the variation in $\beta$-gal enzyme species and the enzyme to substrate ratio to achieve higher GOS yields. In contrast, this contribution is focused on the kinetic mechanism control by selective enzymatic reduction of side products using a coupling reaction to intensify the process in approach I as well as a successful substitution of the substrate as studied in approach II. Both concepts provide an independent opportunity for process control, reduction of the by-products and to achieve highest GOS yields.

The application of glucose oxidase to convert the side product glucose in a subsequent coupling reaction revealed a complex change in reaction mechanism and no significant increase in GOS yield. But the results also indicate the requirement of a suitable enzyme activity relation between the species $\beta$-galactosidase and glucose oxidase as well as the timing of the glucose oxidase dosage might be of high importance.

However, magnesium, potassium and sodium chloride indicated an enrichment in the GOS yield, reasoned by coenzyme/activator properties of the minerals using approach II. Whereas calcium chloride possesses inhibiting effects on the GOS formation. The positive effects of the minerals can be transferred to the results obtained with the substrate substitution of lactose with industrial sweet whey and sweet whey permeate, whereas the GOS yield was extended by up to $6.4 \%$.

\section{Acknowledgements}

The authors gratefully acknowledge the funding by the German Federal Ministry of Education and Research (BMBF) within the framework of the FHprofUnt 2014 (project number: 03FH017PX4).

\section{Abbreviations}

GOS Galacto-oligosaccharides

$\beta-g a l$ $\beta$-galactosidase 


$\begin{array}{ll}\text { GOx } & \text { Glucose oxidase } \\ \text { CAT } & \text { Catalase } \\ \text { O-NPG } & \text { o-nitrophenyl- } \beta \text {-D-galactopyranoside } \\ \text { ILC } & \text { Initial lactose concentration } \\ \text { K. lactis } & \text { Kluyveromyces lactis } \\ \text { E. coli } & \text { Escherichia coli }\end{array}$

References:

[1] M. Roberfroid et al., British Journal of Nutrition 2010, 104 (S2), S1-S63. DOI: 10.1017/S0007114510003363.

[2] M. G. Gänzle, G. Haase, P. Jelen, International Dairy Journal 2008, 18 (7), 685-694. DOI: 10.1016/j.idairyj.2008.03.003.

[3] H. G. Kessler, Lebensmittel- und Bioverfahrenstechnik: Molkereitechnologie. Kessler, 1988.

[4] L. Glass, T. I. Hedrick, Journal of Dairy Science 1977, 60 (2), 190-196. DOI: 10.3168/jds.S0022-0302(77)83853-8.

[5] C.-C. Cheng et al., Biotechnology letters 2006, 28 (11), 793-797. DOI: 10.1007/s10529-006-9002-1.

[6] J. Prenosil, E. Stuker, J. Bourne, Biotechnology and Bioengineering 1987, 30 (9), 1019-1025. DOI: 10.1002/bit.260300904.

[7] J. B. Smart, Applied Microbiology and Biotechnology 1991, 34 (4), 495-501. DOI: 10.1007/bf00180577.

[8] D. F. M. Neri et al., Food Chemistry 2009, 115 (1), 92-99. DOI: 10.1016/j.foodchem.2008.11.068.

[9] C. Fischer, T. Kleinschmidt, International Dairy Journal 2015, 48, 15-22. DOI: 10.1016/j.idairyj.2015.01.003.

[10] R. Huber, C. Parfett, H. Woulfe-Flanagan, D. Thompson, Biochemistry 1979, 18 (19), 4090-4095. DOI: 10.1021/bi00586a005.

[11]C. W. Hall, T. I. Hedrick, Drying milk and milk products. 1966. DOI: 10.1002/food.19670110746.

Fig. 1: Simplified equilibrium-limited reaction mechanism of GOS synthesis

Fig. 2: Extended reaction mechanism of GOS synthesis by glucose conversion with glucose oxidase (GOx) to gluconic acid and neutralisation agent catalase (CAT)

Fig. 3: GOS batch kinetics of a) lactose (rhombus) conversion, glucose (circles) formation and GOS (triangles) yield in comparison of the reference reaction (dashed lines/open symbols) to the reaction w/ GOx/CAT (lines/filled symbols) and $\mathbf{b}$ ) change of oxygen saturation (cubus) of the solution between the reference reaction (dashed lines/open symbols) and w/ GOx/CAT (lines/filled symbols) measured with a pO2-electrode; $\beta$-gal from $K$. lactis

Fig. 4: Impact of a) the mineral types $\mathrm{CaCl}_{2}, \mathrm{MgCl}_{2}, \mathrm{NaCl}_{2}, \mathrm{KCl}$ at a concentration of $1 \mathrm{mmol} \mathrm{L}^{-1}$ and b) the mineral concentration ( $\mathrm{KCl}$ as example) on lactose conversion (bars) and $\mathrm{GOS}$ yield (lines with data points) after six hours reaction catalyzed by $\beta$-gal from $E$. coli

Fig. 5: Development of GOS yield of reference substrate lactose (solid line/triangles) in comparison with the substitution substrates sweet whey (dotted line/rhombus) and sweet whey permeate (dashed line/circles) 


\section{Text for table of content}

This work provides two divergent approaches regarding to enhance the enzymatic production of prebiotic galacto-oligosaccharides. In the first concept the shift of reaction equilibrium and in the second a process intensification by substrate substitution will be examined. 